

\title{
Pengaruh Budaya Keuangan, dan Keputusan Pembayaran Kredit Terhadap Peluang Akses Layanan Keuangan UMKM Lombok
}

\author{
Sulkiah \\ Universitas Gunung Rinjani \\ Email: Chunk_6@yahoo.com \\ ABSTRAK
}

Studi empiris terakhir menunjukkan bahwa akses keuangan merupakan kendala UKM untuk tumbuh. Melihat kondisi ini, OJK menetapkan peraturan terkait dengan pembiayaan online UKM (equity crowdfunding) yang tengah booming di dunia keuangan. Penelitian ini menganalisis pengaruh budaya keuangan, dan keputusan pembayaran kredit terhadap akses keuangan. Pengambilan sampel didasarkan pada jenis usaha dan kategori usaha kecil dan menengah. Data dikumpulkan dari penyebaran kuesioner terhadap 171 UKM di Lombok menggunakan pendekatan door to door dan pendampingan pengisian. Data diuji statistik untuk analisis deskriptif, validitas dan reliabilitas, dan regresi linear. Hasil penelitian menunjukkan adanya pengaruh positif dari budaya keuangan, dan keputusan pembayaran kredit terhadap akses keuangan UKM . Temuan ini menunjukkan pentingnya budaya keuangan UKM untuk mengakses pendanaan eksternal. UKM dapat meningkatkan kapasitas dan kemauan UKM untuk mengajukan pendanaan. Hasil penelitian juga memberikan kontribusi literasi di bidang keuangan terkait dengan aksesibilitas UKM pada pembiayaan dan keputusan pembayaran kredit, serta budaya keuangan.

Kata kunci: Akses Keuangan; Budaya Keuangan; UKM.

\section{PENDAHULUAN}

Usaha kecil dan menengah (UKM) telah terbukti menjadi bagian penopang ekonomi nasional. Hal ini terlihat sejak awal krisis moneter tahun 1997-1998, hanya UKM lah yang mampu bertahan. Kurangnya akses pada layanan keuangan terutama lembaga formal (baik bank atau non bank) adalah masalah klasik dalam pengembangan, pertumbuhan, keberhasilan dan kinerja UKM (Ahiawodzi \& Adade, 2012; Angilella \& Mazzù, 2015; Fowowe, 2017; Ikasari et al., 2016; Machmud \& Huda, 2011). Ketersediaan keuangan telah disorot sebagai faktor utama dalam keberhasilan dan kinerja UKM. Masalah akses sumber keuangan untuk UKM ada ketika kegiatan bisnis yang akan dibiayai secara internal tidak mendapatkan dukungan dari lembaga keuangan eksternal.

Lebih dari 58\% Produk Domestik Bruto (PDB) Indonesia ditopang dari UKM dan mampu menyerap tenaga kerja hingga 97\%. Prospek usaha kecil dan menengah perlu ditingkatkan terus menerus untuk kesejahteraan masyarakat dan pertumbuhan ekonomi. Bagi UKM, akses keuangan merupakan faktor pendorong pertumbuhan (Adomako et al., 2015; Ahiawodzi \& Adade, 2012) dan kinerja usaha (Fowowe, 2017; Harash et al., 2014). Namun, akses keuangan masih menjadi kendala utama keberlanjutan bisnis (Lee et 
al., 2013, 2015; Venturelli, 2008). Penyerapan pembiayaan bagi UKM di Indonesia masih tergolong sangat rendah. Berdasarkan data yang diperoleh dari website resmi Otoritas Jasa Keuangan (OJK) Republik Indonesia per Oktober 2020 menunjukkan hanya sebesar 15,58\% atau senilai 72.949 miliar rupiah pembiayaan yang berhasil diserap oleh UKM. Penyerapan itu masing-masing adalah 4,32\% atau senilai 20.244 miliar rupiah oleh usaha kecil dan $11,26 \%$ atau senilai 52.705 miliar rupiah oleh usaha menengah. Ini masih tergolong kategori rendah. Angka ini menunjukkan UKM masih kesulitan untuk mengakses pembiayaan ke lembaga keuangan.

Minimnya penyaluran pembiayaan karena terkendala administrasi dan manajemen keuangan UKM yang rendah. Upaya Pemerintah khusus kepada pelaku usaha kecil dan menengah dalam kemudahan akses ke lembaga keuangan dengan koordinasi bersama bankbank untuk memfasilitasi Kredit Usaha Rakyat (KUR). Bahkan, kebijakan equity crowdfunding resmi dirilis oleh OJK dalam rangka membantu UKM memperoleh dana melalui penawaran saham berbasis teknologi. Namun, faktor-faktor internal perusahaan yang menunjukkan kualitas dan fleksibilitas keuangan bisnis juga perlu untuk dianalisis.

Penelitian ini mencoba berkontribusi pada literatur dengan menyelesaikan masalah dari sudut pandang yang berbeda. Tidak dapat dipungkiri bahwa UKM juga memerlukan pembiayaan untuk membiayai dan memperluas bisnis mereka. Namun, untuk melakukannya UKM sering kali kesulitan mengakses ke layanan keuangan karena terjadinya kesenjangan keuangan (Machmud \& Huda, 2011). Lembaga keuangan formal mengklasifikasikan UKM sebagai perusahaan unbankable. Pinjaman bank adalah sumber pendanaan eksternal yang penting bagi UKM. Namun birokrasi yang terkadang membuat UKM enggan mengajukan permohonan dana.

Penelitian ini mencoba menganalisis faktor-faktor apa yang dapat mempengaruhi aksesibilitas UKM ke layanan keuangan. Beberapa studi empiris mendokumentasikan ada perbedaan antara pemilik laki- laki dan pemilik perempuan dalam mengakses layanan keuangan (Arenius \& Autio, 2006; Gazanchyan et al., 2017; Scott \& Irwin, 2007; Treichel \& Scott, 2006; Wellalage \& Locke, 2017). Faktor-faktor kepribadian tidak dipertimbangkan disana. Untuk itu penelitian ini mencoba menganalisis pengaruh budaya keuangan, dan keputusan pembayaran kredit terhadap peluang akses layanan keuangan.

Kajian literatur dan fenomena yang terjadi memunculkan satu pertanyaan penelitian, apa yang menyebabkan akses ke keuangan UKM lebih sulit? Oleh kaena itu, penelitian ini bertujuan untuk menganalisis pengaruh budaya keuangan, dan keputusan UKM untuk pembayaran kredit terhadap peluang akses layanan keuangan baik secara parsial maupun simultan.

\section{TINJAUAN PUSTAKA}

\section{Akses Keuangan}

Akses ke keuangan mengacu pada kemungkinan bahwa individu atau perusahaan dapat mengakses layanan keuangan (Mertzanis, 2017). Akses keuangan sangat penting untuk penyediaan keuangan yang efektif untuk pengembangan perusahaan dan memungkinkan perusahaan untuk tumbuh dengan mengeksploitasi pangsa pasar dan peluang investasi. Pada gilirannya, membawa manfaat bagi ekonomi dengan mempercepat pertumbuhan ekonomi, mengintensifkan persaingan, serta meningkatkan pendapatan mereka dan mengurangi kemiskinan. Akses ke keuangan adalah kemampuan individu atau perusahaan untuk mendapatkan layanan keuangan, seperti kredit, deposito, payment, asuransi dan layanan lainnya (Demirgüç-Kunt et al., 2008). Menurut Ikasari et al., (2016), mudah atau tidaknya akses ke keuangan dapat dilihat dari 2 aspek yaitu aksesibilitas, kelayakan, dan keterjangkuan/kemampuan. Aksesibilitas yaitu kedekatan jarak rumah 
atau perusahaan dengan bank serta kemudahan mengakses ke tujuan. Sedangkan kelayakan kredit diukur melalui pengetahuan pemilik UKM terhadap berbagai layanan keuangan yang ditawarkan oleh bank beserta prosedur permohonan kredit dan kemampuan untuk menyediakan jaminan serta seluruh dokumen yang dibutuhkan untuk permohonan kredit. Untuk keterjangkauan kredit dilihat dari kemudahan UKM untuk menyediakan dokumen yang dibutuhkan untuk permohonan kredit dan tingkat bunga kredit.

\section{Budaya Keuangan}

Budaya keuangan terdiri dari beberapa aspek yaitu kesejahteraan keuangan, perilaku keuangan, sikap keuangan, perspektif waktu dan kemampuan untuk menunda kepuasan (Zsótér, 2018). Elemen-elemen ini tidak mencakup seluruh definisi budaya keuangan, tetapi elemen-elemen tersebut sangat penting dalam budaya keuangan perusahaan. Rumyantseva (2013) menyebutkan tingkat budaya keuangan adalah kunci kesejahteraan keuangan dan peningkatan produktivitas perusahaan. Dengan demikian budaya keuangan yang buruk menyebabkan terjadinya inefisiensi transaksi keuangan yang mana menunjukkan kualitas manajemen keuangan yang buruk. Keadaan yang buruk tersebut akan terbaca oleh lembaga keuangan dan menghambat akses pembiayaan perusahaan.

\section{Pembayaran Kredit}

Perilaku kredit UKM akhir-akhir ini sering dibahas sebagai fitur pengukur risiko kredit UKM (McHugh \& Ranyard, 2012, 2016; Mutegi et al., 2015; Siddiqui, 2017; Wang, 2012). Perilaku pembayaran pinjaman yang buruk merupakan masalah utama yang dihadapi oleh kebanyakan lembaga keuangan (Siddiqui, 2017). Faktor pembayaran pinjaman terdiri dari tiga pelaku yaitu karakteristik peminjam, perusahaan, dan pemberi pinjaman (Siddiqui,2017). Studi tersebut menunjukkan bahwa ketika pinjaman tidak dilunasi, itu mungkin akibat ketidakmauan peminjam atau ketidakmampuan untuk membayar. Riset yang dilakukan oleh Ismanto \& Diman (2014) menyebutkan bahwa efektivitas pemberian pinjaman kepada UMKM dipengaruhi oleh pendapatan usaha, lama usaha, dan nilai pinjaman. Selain itu, persyaratan agunan dan kecukupan jumlah pinjaman juga merupakan faktor penting yang mempengaruhi perilaku pembayaran. Karakteristik peminjam termasuk didalamnya perilaku membayar berhubungan dengan keputusan pembayaran pinjaman. Berdasarkan model mekanisme, fitur kredit pengusaha diperlakukan dalam dua aspek yaitu kapasitas kredit dan kemauan kredit (Wang, 2012). Karakterkarakter dasar kedua aspek tersebut mewakili perilaku pemilik, dan selanjutnya berdampak pada risiko kredit perusahaan. Kapasitas kredit seperti pendapatan usaha dan kemampuan menangani kesulitan keuangan akan menentukan keputusan pembayaran kredit.

\section{UKM}

Mutegi et al., (2015) menyebutkan bahwa ada empat keterampilan yang harus dimiliki UKM dan sangat menentukan UKM untuk membayar pinjamannya, empat keterampilan itu meliputi manajemen kredit yang yang tepat, keterampilan pembukuan, keterampilan penganggaran, dan keterampilan analisis keuangan. Kombinasi keempat keterampilan tersebut akan membantu UKM untuk mengambil keputusan pembayaran kredit. Manajemen kredit yang tepat akan dapat memberikan informasi kredit perusahaan termasuk biaya pinjaman, ukuran pinjaman, tingkat bunga dan informasi lainnya. McHugh \& Ranyard (2012,

2016) menyebutkan bahwa keputusan pembayaran pinjaman memiliki efek 
signifikan terhadap tingkat pembayaran pinjaman. Keputusan pembayaran cicilan secara rutin menunjukkan UKM memenuhi kewajibannya dengan baik sehingga tingkat pembayaran pinjamannya terjamin. Tingkat pembayaran yang rendah cenderung akan mengurangi kepercayaan bank untuk memberikan pinjaman kepada UKM tersebut. Yang dengan demikian, akses ke layanan keuangan menjadi terhambat.

\section{Kerangka Pemikiran}

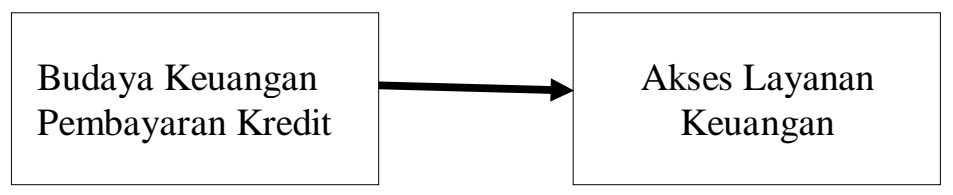

\section{Hipotesis}

H1: Ada pengaruh budaya keuangan UKM terhadap peluang akses layanan keuangan

H2: Ada pengaruh keputusan UKM untuk pembayaran kredit terhadap peluang akses layanan keuangan.

\section{METODOLOGI PENELITIAN \\ Tempat dan Waktu Penelitian}

Penelitian ini dilaksanakan di UKM Lombok selama 1 tahun sampai dengan maret 2021.

\section{Metode Penelitian}

Penelitian ini menggunakan pendekatan kuantitatif untuk menguji data primer. Data diperoleh melalui hasil kuesioner yang telah diisi oleh pengusaha UKM di wilayah Lombok. Peneliti mengunjungi pengusaha UKM secara langsung (door to door) untuk meminta kesediaan mengisi kuesioner. Penelitian dilakukan selama bulan Januari 2020 hingga Januari 2021.

\section{Populasi dan Sampel}

Pengambilan sampel menggunakan metode proportional random sampling berdasarkan jenis industri kecil dan menengah. Jumlah sampel ditentukan berdasarkan rumus Slovin dengan tingkat kesalahan $10 \%$ dari jumlah populasi UKM di Lombok sebanyak 4571 unit usaha dan dihasilkan 171 unit usaha. Namun dalam perjalanannya, UKM yang sulit aksesnya saja yang dijadikan sampel dan diberikan sebanyak 171 kuesioner yang berhasil dikumpulkan dan dinyatakan valid. Jumlah ini yang selanjutnya digunakan dalam analisis deskriptif dan regresi. Data diolah menggunakan perangkat lunak Smart-PLS untuk beberapa uji statistik meliputi analisis deskriptif, uji validitas dan reliabilitas, dan pengujian hipotesis.

\section{Identifikasi Variabel}

Variabel penelitian antara lain akses ke keuangan (ACC), budaya keuangan (CUL), dan keputusan pembayaran kredit (REY) sebagaimana dalam Gambar 1. Variabel dependen penelitian ini adalah akses ke keuangan yang mengacu pada Ikasari et al. (2016). Variabel akses ke keuangan dilihat dari tiga indikator yaitu aksesibilitas, keterjangkauan dan kelayakan. Untuk daya saing diukur menggunakan indikator dari Carvalho \& Costa (2014) yaitu pendapatan, pangsa pasar, kepuasan, nilai perusahaan dan nilai produk/jasa yang semuanya dirangkum dalam lima pertanyaan. Pengukuran variabel budaya keuangan mengikuti item yang digunakan oleh Rumyantseva (2013). Ada enam pertanyaan untuk 
variabel ini meliputi budaya dalam proses keuangan, komunikasi, pemetaan pasar, pemahaman konsep keuangan, laporan keuangan dan penetapan target. Untuk variabel keputusan pembayaran kredit mengadopsi indikator McHugh \& Ranyard (2016) dan enam pertanyaan mewakilinya. Penilaian variabel-variabel penelitian menggunakan skala skor 1 sampai 6. Untuk pertanyaan positif, 1 skor untuk "sangat tidak setuju" dan 6 skor untuk "sangat setuju". Sedangkan untuk pertanyaan negatif, 1 skor untuk "sangat setuju" dan 6 skor untuk "sangat tidak setuju".

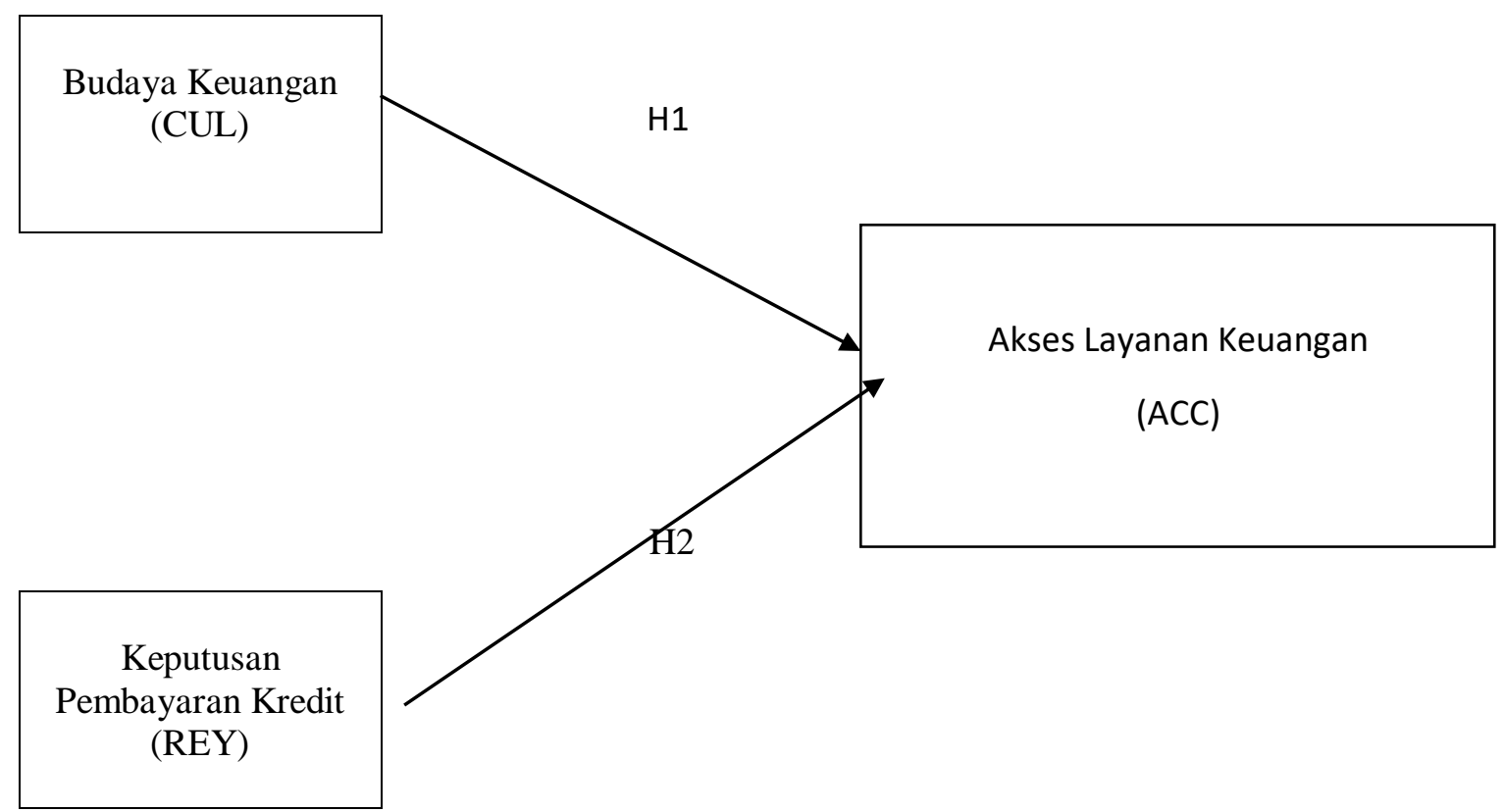

Gambar 1. Kerangka Penelitian

\section{HASIL DAN PEMBAHASAN}

Instrumen penelitian diuji validitas dan reliabilitas terlebih dahulu untuk melihat apakah instrumen adalah valid dan mewakili populasi. Pengujian ini digunakan untuk mempresentasikan setiap konstruk yang dapat diketahui dengan cara melihat convergent validity yang diukur dengan menggunakan nilai Average Variance Ectracted (AVE) sebagaimana nilai AVE harus > 0,5 (Ghozali \& Latan, 2015). Seluruh konstruk yang digunakan dalam penelitian ini menunjukkan convergent validity yang baik. Setiap indikator pengukuran terhadap variabel penelitian memiliki nilai yang tidak sama, diketahui dari nilai outer loading berada di atas 0,6. Nilai outer loading pada Tabel 1 memperlihatkan bahwa semua indikator pertanyaan sudah valid. 
Tabel 1. Outer Loading Instrumen Penelitian

\begin{tabular}{cccc}
\hline Item & $\begin{array}{c}\text { Akses Layanan } \\
\text { Keuangan (ACC) }\end{array}$ & $\begin{array}{c}\text { Budaya } \\
\text { Keuangan (CUL) }\end{array}$ & $\begin{array}{c}\text { Keputusan } \\
\text { Pembayaran } \\
\text { Kredit (REY) }\end{array}$ \\
\hline ACC1 & 0,871 & & \\
ACC2 & 0,828 & & \\
ACC3 & 0,819 & & \\
ACC4 & 0,850 & & \\
ACC5 & 0,810 & & \\
ACC6 & 0,744 & 0,864 & \\
CUL1 & & 0,850 & \\
CUL2 & & 0,867 & \\
CUL3 & & 0,816 & \\
CUL4 & & 0,780 & \\
CUL5 & & 0,881 & \\
CUL6 & & & 0,830 \\
REY1 & & & 0,794 \\
REY2 & & & 0,787 \\
REY3 & & & 0,828 \\
REY4 & & & 0,741 \\
REY5 & & & \\
REY6 & & & \\
\hline
\end{tabular}

Sumber: Data yang diolah

Untuk memastikan bahwa instrumen-instrumen variabel telah konsisten dan akurat, instrumen-instrumen tersebut diperiksa reliabilitasnya melalui nilai conbach's alpha. Dalam Tabel 2 menunjukkan bahwa semua variabel adalah reliabel, yaitu di atas 0,7. Kemudian nilai konstruk dari setiap konstruk lebih besar dari konstruk lainnya dan di atas nilai 0,7 , sehingga validitas diskriminan terpenuhi.

Tabel 2. Hasil Pengujian Validitas dan Reliabilitas

\begin{tabular}{lccc}
\hline & $\begin{array}{l}\text { Akses } \\
\text { Layanan. } \\
\text { Keuangan } \\
\text { (ACC) }\end{array}$ & $\begin{array}{c}\text { Budaya } \\
\text { Keuangan } \\
\text { (CUL) }\end{array}$ & $\begin{array}{c}\text { Keputusan } \\
\text { Pembayaran } \\
\text { Kredit (REY) }\end{array}$ \\
\hline $\begin{array}{l}\text { Akses Keuangan } \\
\text { Budaya Keuangan }\end{array}$ & 0,821 & & \\
$\begin{array}{l}\text { Keputusan Pembayaran } \\
\text { Kredit }\end{array}$ & 0,423 & 0,844 & 0,791 \\
$\begin{array}{l}\text { Cronbach 's Alpha } \\
\text { Average Variance Extracted } \\
\quad \text { (AVE) }\end{array}$ & 0,424 & 0,552 & 0,882 \\
\hline
\end{tabular}

Sumber: Data yang diolah

Lombok merupakan salah satu kota kecil yang produktif, karena setidaknya ada 13 jenis industri kecil dan menengah yang berkembang (BPS NTB, 2018). Industri kecil dan menengah tersebut antara lain furnitur, genteng, gerabah, kerajinan kayu, kerajinan rotan, konveksi dan bordir, mainan anak, makanan, monel, dan tenun ikat. Karakterisrik responden dan bisnisnya teringkas dalam Tabel 3 di bawah alinea ini. Sebagian besar 
responden memiliki usaha furnitur $(29,7 \%)$, ini karena Lombok sendiri merupakan usaha yang beragam. Usaha yang dijalankan responden saat ini sebagian besar adalah usaha turun temurun. $27 \%$ usaha yang berjalan selama 5-10 tahun dan selebihnya (73\%) berjalan lebih dari 10 tahun. Sedangkan, pemilik usaha didominasi oleh laki-laki $(77,5 \%)$ dan paling banyak berusia berkisar 40-49 tahun (30,9\%) dan 50-59 tahun (34,4\%). Usia-usia muda dan produktif yaitu usia 20-29 tahun hanya 12.3\% dan usia 30-39 tahun hanya 14,0\%, sedangkan selebihnya berusia lanjut. Menurut tingkat pendidikan, sebagian besar responden berasal dari tingkat pendidikan rendah yaitu sekolah dasar sebanyak 34\%. Untuk yang pernah mengenyam pendidikan tinggi hanya $8 \%$, selebihnya dari SMP $(26,3 \%)$ dan SMA $(31,6 \%)$.

Tabel 3. Profil Responden dan UsaHa yang DIjalanKan

\begin{tabular}{|c|c|c|c|}
\hline KarakterIstik & Kategori & FrekuensI & Persen (\%) \\
\hline \multirow[t]{2}{*}{ Jenis KelamIn } & Laki-laki & 107 & 62,57 \\
\hline & Perempuan & 64 & 37,43 \\
\hline \multirow[t]{6}{*}{ Usia (tahun) } & $20-29$ & 30 & 17,50 \\
\hline & $30-39$ & 48 & 28,07 \\
\hline & $40-49$ & 62 & 36,26 \\
\hline & $50-59$ & 23 & 13,45 \\
\hline & $60-69$ & 7 & 4,09 \\
\hline & $>70$ & 1 & 0,58 \\
\hline \multirow[t]{4}{*}{ Pendidikan terakhir } & SD-Sederajat & 51 & 29,82 \\
\hline & SMP-Sederajat & 50 & 29,24 \\
\hline & SMA-Sederajat & 52 & 30,41 \\
\hline & Diploma atau Sarjana (S-1) & 18 & 10,53 \\
\hline \multirow[t]{8}{*}{ Jenis Usaha } & Furnitur & 23 & 13,45 \\
\hline & Genteng & 37 & 21,64 \\
\hline & Gerabah & 39 & 22,81 \\
\hline & Kerajinan Kayu/Rotan & 28 & 16,37 \\
\hline & Konveksi dan bordir & 27 & 15,79 \\
\hline & Mainan anak & 3 & 1,75 \\
\hline & Monel & 5 & 2,92 \\
\hline & Tenun Ikat & 9 & 5,26 \\
\hline \multirow[t]{8}{*}{ Lama Usaha (tahun) } & $5-10$ & 15 & 8,77 \\
\hline & $11-15$ & 37 & 21,64 \\
\hline & $16-20$ & 9 & 5,26 \\
\hline & $21-25$ & 21 & 12,28 \\
\hline & $26-30$ & 27 & 15,79 \\
\hline & $31-35$ & 21 & 12,28 \\
\hline & $36-40$ & 21 & 12,28 \\
\hline & $>40$ & 20 & 11,69 \\
\hline
\end{tabular}

Sumber: Data yang diolah

Berdasarkan Tabel 4 diperoleh nilai $R$-Square konstruk variabel dependen sebesar 0,272 , ini mengindikasikan bahwa $27,2 \%$ faktor yang menentukan akses ke keuangan UKM berasal dari budaya keuangan, dan keputusan pembayaran kredit, selebihnya ditentukan dari faktor diluar model penelitian ini.

Besarnya pengaruh variabel independen penelitian ini terhadap variabel dependen juga dapat dievaluasi menggunakan hasil uji $t$-statistic. Nilai yang hitung $t$-statistic dibandingkan dengan $t$-table sebesar 1,96 dengan nilai probabilitas 0,05 . Hasil regresi dan $t$ statistic penelitian ini teringkas dalam Tabel 5. Dalam tabel tersebut dapat disimpulkan bahwa semua hipotesis penelitian diterima, baik itu hipotesis alternatif 1 ( (H1) bahwa 
budaya keuangan berpengaruh terhadap akses UKM ke keuangan; dan hipotesis alternatif 2 (H2) bahwa keputusan pembayaran kredit berpengaruh terhadap akses UKM ke keuangan. Simpulan korelasi ini berdasarkan pada hasil t-statistic lebih dari 1,96 dan p-values kurang dari 0,05. Dengan demikian, pengaruh parsial variabel budaya keuangan, dan keputusan pembayaran kredit terhadap akses ke keuangan adalah signifikan.

Tabel 5. Hasil Regresi dan Uji Hipotesis

\begin{tabular}{llllll}
\hline & $\begin{array}{c}\text { Original } \\
\text { Sample }\end{array}$ & $\begin{array}{c}\text { Standard } \\
\text { Deviation }\end{array}$ & T-statistics & p-values & Keputusan \\
\hline CUL $\rightarrow$ ACC & 0,226 & 0,076 & 2,973 & 0,003 & Diterima \\
REY $\rightarrow$ ACC & 0,231 & 0,066 & 3,521 & 0,000 & Diterima \\
\hline
\end{tabular}

Sumber: Data diolah, 2020

Organisasi membentuk budaya dan budaya adalah organisasi itu sendiri (Van Der Post et al., 1998). Kalimat itu mendeskripsikan bahwa setiap organisasi membentuk atmosfer lingkungan kerja. Budaya kerja yang tumbuh menjadi kebiasaan dalam perusahaan akan berdampak pada aktivitas operasional perusahaan, baik itu kebiasaan baik yang mengarah pada peningkatan kinerja atau justru kebiasaan buruk yang mengakibatkan penurunan kinerja. Apalagi terkait dengan keuangan, yang notabennya merupakan bagian krusial keberlangsungan bisnis. Potensi kecurangan lebih besar ketika karyawan dihadapkan pada uang dalam jumlah yang besar sehingga manajemen dan pencatatan keuangan menjadi sangat penting. Budaya keuangan yang dibangun pemilik UKM dapat membantu mengurangi kecurangan dan kesejahteraan lebih terjamin. Seperti halnya yang disebutkan oleh Rumyantseva (2013) bahwa budaya keuangan merupakan kunci kesejahteraan keuangan dan produktivitas perusahaan yang melibatkan pengetahuan dan kemampuan hukum-ekonomi dalam pengambilan keputusan. Ketika kesejahteraan keuangan terjaga, maka potensi aksesibilitas UKM terbuka lebih lebar. Sesuai dengan hasil empiris penelitian ini, bahwa budaya keuangan berpengaruh positif terhadap akses UKM ke keuangan.

Selanjutnya, statistik penelitian ini menemukan adanya pengaruh positif dari keputusan pembayaran kredit terhadap akses UKM ke keuangan. Hasil ini sejalan dengan McHugh \& Ranyardn $(2012$, 2016) yang menemukan bahwa keputusan pembayaran pinjaman memiliki efek signifikan terhadap tingkat pembayaran pinjaman. Tingkat pembayaran pinjaman dapat menggambarkan kemampuan debitur membayar pinjamannya. Keputusan pembayaran cicilan secara rutin menunjukkan UKM memenuhi kewajibannya dengan baik sehingga tingkat pembayaran pinjamannya terjamin. Rasa kekhawatiran pembayaran pinjaman di masa depan dapat teratasi dengan konsistensi pembayaran pinjaman. Dengan demikian, trust lembaga keuangan meningkat dan akses ke keuangan lebih mudah.

\section{KESIMPULAN DAN SARAN}

Akses ke layanan keuangan merupakan fitur penting dalam operasi bisnis UKM. Berbeda dari perusahaan besar, UKM menunjukkan personalisasi karena perkembangannya bergantung pada pengusaha yang sekaligus adalah pemilik dan pendiri. Efek personalisasi tersebut yang menyebabkan keraguan bank terhadap perilaku pembayaran kembali kredit yang diambil. Hasil penelitian ini menunjukkan bahwa akses UKM ke keuangan dipengaruhi budaya keuangan, dan keputusan pembayaran kredit. Temuan ini memberikan literasi di bidang keuangan terkait dengan aksesibilitas UKM pada pembiayaan dan 
keputusan pembayaran kredit, serta budaya keuangan. Dapat disimpulkan bahwa kapasitas (budaya) dan kemauan (keputusan) pembayaran pinjaman menentukan aksesibilitas UKM ke pembiayaan. Akan tetapi, di sisi lain, UKM masih mengeluhkan sulitnya akses mereka pada pembiayaan di lembaga keuangan konvensional. Padahal, suntikan dana eksternal ini dapat digunakan UKM untuk mengembangkan usahanya dan memperluas pasar mereka. Penelitian ini tidak lepas dari keterbatasan, namun keterbatasan itu tidak mengurangi kualitas hasil penelitian ini. Keterbatasan yang terjadi selama di lapangan adalah sulitnya memperoleh kesediaan responden untuk bekerja sama dalam penelitian. Selain itu, beberapa responden mengalami kesulitan memahami beberapa pertanyaan dalam kuesioner sehingga perlu adanya pendampingan dan penjelasan. Penelitian selanjutnya dapat mengembangkan instrumen pengukuran variabel-variabel dalam penelitian ini berdasarkan kajian studi empiris dan memperluas sampling berdasarkan jenis usaha dan wilayah. Pengujian hubungan variabel-variabel lain terkait dengan UKM juga dapat dikaji lebih lanjut, seperti keterkaitan budaya keuangan terhadap kinerja keuangan dan produktivitas.

\section{REFERENSI}

Adomako, S., Danso, A., \& Damoah, J. O. (2015). The Moderating Influence of Financial Literacy on The Relationship Between Access to Finance and Firm Growth in Ghana. Venture Capital, 18(1), 43-61. https://doi.org/10.1080/13691066.2015.1079952

Ahiawodzi, A. K., \& Adade, T. C. (2012). Access to Credit and Growth of Small and Medium Scale Enterprise in the Ho Municipality of Ghana. British Journal of Economics, Finance and Management Sciences, 6(2), 34-51.

Ahmedova, S. (2015). Factors for Increasing the Competitiveness of Small and Medium- Sized Enterprises (SMEs) in Bulgaria. Procedia - Social and Behavioral Sciences, 195,1104-1112. https://doi.org/10.1016/j.sbspro.2015.06.15

Angilella, S., \& Mazzù, S. (2015). The Financing of Innovative SMEs: A Multicriteria Credit Rating Model. European Journal of Operational Research, 244(2), 540-554. https://doi.org/https://doi.org/10.1016/j.ejor.2015.01.033

Anton, S. A., Muzakan, I., Muhammad, W. F., Syamsudin, \& Sidiq, N. P. (2015). An Assessment of SME Competitiveness in Indonesia. Journal of Competitiveness, 7(2), 60-74. https://doi.org/10.7441/joc.2015.02.04

Arenius, P., \& Autio, E. (2006). Financing of Small Businesses: Are Mars and Venus More Alike than Different? Venture Capital, 8(2), 93-107. https://doi.org/10.1080/13691060500433793

Breuer, W., \& Quinten, B. (2009). Cultural Finance. Available at SSRN 1282068. https://doi.org/http://dx.doi.org/10.2139/ssrn.1282068 Carvalho, L., \&

Costa, T. (2014). Small and Medium Enterprises (SMEs) and Competitiveness: An Empirical Study. Management Studies, 2(2), 88-95.

Ceptureanu, S. lon. (2015). Competitiveness of SMEs. Business Excellence and Management,5(2), 55-67.

Csiszárik-kocsir, Á., Varga, J., \& Fodor, M. (2016). The Value Based Analysis of the Financial Culture. The Journal of Macrotrends in Social Science, 2(1), 89-100.

Demirgüç-Kunt, A., Honohan, P., \& Beck, T. (2008). Finance for All: Policies and Pitfalls in

Expanding Access. The World Bank.

Fowowe, B. (2017). Access to Finance and Firm Performance: Evidence from 
African Countries. Review of Development Finance, 7(1), 6-17. https://doi.org/10.1016/j.rdf.2017.01.006

Gazanchyan, N. S., Hashimzade, N., Rodionova, Y., \& Vershinina, N. (2017). Gender, Access to Finance, Occupational Choice, and Business Performance, CESifo Working Paper, No. 6353, Center for Economic Studies and Ifo Institute (CESifo), Munich.

Ghozali, I., \& Latan, H. (2015). Partial Least Squares: Konsep, Teknik dan Aplikasi Menggunakan Program SmartPLS 3.0 (2nd ed.). Badan Penerbit Universitas Diponegoro

Harash, E., Al-timimi, S., \& Alsaadi, J. (2014). The Influence of Finance on Performance of Small and Medium Enterprises ( SMES ). International Journal of Engineering and Innovative Technology, 4(3), 161-167.

Ikasari, N., Sumransat, T., Eko, U., \& Kusumastuti, R. (2016). Access of Small and Medium Enterprises to Finance in Rural Areas: Case of Indonesia and Thailand. International Journal of Economics and Management Engineering, 10(5), 1661-1668.

Ismanto, H., \& Diman, T. (2014). Analisis Efektivitas Pemberian Pinjaman Program Pembiayaan UMKM oleh Koperasi. Jurnal Economia, 10(2), 148-164. https://doi.org/10.21831/economia.v10i2.7541

Karaev, A., Koh, S. C. L., \& Szamosi, L. T. (2007). The Cluster Approach and SME Competitiveness: A Review. Journal of Manufacturing Technology Management, $18(7)$,

818-835. https://doi.org/10.1108/17410380710817273

Laureti, T., \& Viviani, A. (2011). Competitiveness and Productivity: A Case Study of Italian Firms. Applied Economics, 43(20), 2615-2625. https://doi.org/10.1080/00036840903357439

Lee, N., Sameen, H., \& Cowling, M. (2015). Access to Finance for Innovative SMEs SinceNThe Financial Crisis. Research Policy, 44(2), 370-380.

Lee, N., Sameen, H., \& Martin, L. (2013). Credit and the Crisis: Access to Finance for Innovative Small Firms Since the Recession (Issue June).

Machmud, Z., \& Huda, A. (2011). SMEs' Access to Finance: An Indonesia Case Study. In ERIA Research Project Report 201014 (pp. 261-290).

McHugh, S., \& Ranyard, R. (2012). Credit Repayment Decisions: The Role of Long-Term Consequence Information, Economic and Psychological Factors. Review of Behavioral Finance, 4(2), 98-112. https://doi.org/10.1108/19405971211284880

McHugh, S., \& Ranyard, R. (2016). Consumers' Credit Card Repayment Decisions: The Role of Higher Anchors and Future Repayment Concern. Journal of Economic Psychology, 52(February), 102-114. https://doi.org/10.1016/j.joep.2015.12.003

Mertzanis, C. (2017). Marketing Financial Services and Products in Different Cultural Environments. In Information Resources Management Association (Ed.), Risk and Contingency Management: Breakthroughs in Research and Practice: Breakthroughs in Research and Practice (pp. 134-160). IGI Global.

Mutegi, H. K., Njeru, P. W., \& Ongesa, N. T. (2015). Financial Literacy and its Impact on Loan Repayment by Small and Medium Enterpreneurs. International Journal of Economics, Commerce and Management, III(3), 1-28. http://ijecm.co.uk/

Rumyantseva, A. (2013). The Impact of Financial Culture on The Operating Rates. SaintPetersburg University of Management and Economics, Saint-Petersburg, Russia, 169-176 